\title{
Acute and chronic job stressors among ambulance personnel: predictors of health symptoms
}

\author{
E van der Ploeg, R J Kleber
}

See end of article for authors' affiliations

....................

Correspondence to: Rolf J Kleber, Department of Clinical Psychology,

Utrecht University, P.O box

80.140, 3508 TC Utrecht,

The Netherlands;

R.Kleber@fss.uu.nl

Accepted

1 March 2003
Objectives: To predict symptomatology (post-traumatic distress, fatigue, and burnout) due to acute and chronic work related stressors among ambulance personnel.

Methods: Data were gathered from 123 ambulance workers in The Netherlands in a longitudinal design. At two measurements they completed standardised questionnaires to assess health symptoms, such as the Impact of Event Scale, the Maslach Burnout Inventory, and the Checklist Individual Strength. Acute stressors were assessed with specific questions, and chronic work related stressors were measured with the Questionnaire on the Experience and Assessment of Work.

Results: Most of the ambulance workers had been confronted with acute stressors in their work. They also reported more chronic work related stressors than a reference group. Of the participants, more than a tenth suffered from a clinical level of post-traumatic distress, a tenth reported a fatigue level that put them at high risk for sick leave and work disability and nearly a tenth of the personnel suffered from burnout. Best predictors of symptomatology at time 2 were lack of social support at work and poor communication, such as not being informed about important decisions within the organisation.

Conclusions: Ambulance personnel are at risk to develop health symptoms due to work related stressors. Although, acute stressors are related to health symptoms, such as fatigue, burnout, and post-traumatic symptoms, it was not found to predict health symptoms in the long term. Main risk factors have to do with social aspects of the work environment, in particular lack of support from the supervisor as well as colleagues and poor communication. When implementing workplace interventions these social aspects need to be taken into account.
1 $\mathrm{n}$ the field of occupational health psychology researchers have mostly focused their attention on negative effects of long term work characteristics, in particular chronic work related stressors, such as job overload, shift work, role conflict, and lack of social support. Implications of these sources of work related stress include the effects on worker satisfaction and productivity, mental as well as physical health, absenteeism, and the potential for employer liability (for a review of this topic see Tennant ${ }^{1}$ ). However, the role of acute and intense stressors are often neglected.

Employees working in so called medium or high risk professions, such as fire fighters, and emergency workers, are often confronted with acute stressors or critical incidents. Fire fighters may be exposed to the devastating impact of fire and emergency workers may be confronted with dead or dying people. These professionals may be involved in life threatening situations. Moreover, they are repeatedly exposed to potentially traumatic events. However, the fact that they might experience symptoms similar to those they assist may be unrecognised. ${ }^{2}$

The focus of most researchers examining types and consequences of traumatic work place exposures has been on relatively rare events, such as airplane crashes, shipping disasters, or earthquakes. ${ }^{3}$ Research concerning these events has shown that acute stressors may lead to serious mental disturbances, in particular post-traumatic stress disorder (PTSD). ${ }^{4}$ In the fourth edition of the Diagnostic and Statistical Manual of Mental Disorders (DSM-IV) this disorder is characterised by symptoms following exposure to a traumatic stressor. The symptoms are divided into three clusters: re-experiencing of the specific event, avoidance of trauma related stimuli, and increased emotional arousal. ${ }^{5}$

In a study among fire fighters exposed to a bush fire disaster it was found that the disaster was associated with a rise in the prevalence of mental disorders from $2.7 \%$ to $22.4 \%$. PTSD was the most common disorder (18\%), with major depression-occurring in $10 \%$ of the subjects-being the second most frequent diagnosis. ${ }^{6}$
Ursano et al examined post-traumatic symptoms and depression in disaster workers exposed to traumatic death after the USS Iowa gun turret explosion. ${ }^{7}$ The body handlers were assessed at one, four, and 13 months after the disaster. Intrusive and avoidance symptoms were elevated at all three measurements compared to a control group, and the symptoms decreased in time. For most, recovery appeared to be the norm. However, intrusive and avoidant symptoms persisted in some workers. Approximately 15\% of the respondents reported clinically significant levels of symptoms 13 months after the explosion.

From these studies it may be concluded that disasters negatively affect psychological well being of rescue workers. Although most symptoms decreased in time, results indicated that symptoms could persist for months or even years. How do workers cope with these acute stressors when they are frequently exposed to them? According to Beaton and Murphy, repetitive or frequent exposure to trauma is potentially cumulative and threatening to health and well being. To examine this effect of repetitive exposure to acute stressors a longitudinal research design is needed. However, until now most research concerning these repetitive acute stressors has had a cross sectional design.

Marmar et al suggested that frequent occurring critical incidents which are part of the job can be just as stressful for emergency workers as disaster work. ${ }^{9}$ Emergency workers involved in an unsuccessful cardiopulmonary resuscitation were found to suffer from post-traumatic stress reactions. They experienced vivid, involuntary, and uncontrollable thoughts, feelings and/or mental images concerning their attempts. ${ }^{10}$ Clohessy and Ehlers showed that a substantial

Abbreviations: CIS, Checklist Individual Strength; IES, Impact of Event Scale; QEAW, Questionnaire on the Experience and Assessment of Work; MBI, Maslach Burnout Inventory; PTSD, post-traumatic stress disorder 
proportion of emergency workers $(21 \%)$ who were not exposed to major disasters nevertheless experienced distinct symptoms of PTSD. ${ }^{11}$ The most common symptoms were intrusive memories, feelings of irritability, sleep problems, and a sense of detachment from others. The General Health Questionnaire identified more than half of the emergency workers with these PTSD symptoms as psychiatric cases. The results of this study also pointed to a high level of relatively permanent stressors that were chronically present in the work situation. Examples were time pressure and shift work. They contributed to overall distress and to the PTSD symptoms. Emergency workers have often to deal with time pressure in their job, especially in life threatening situations. Working under such pressure of time may be stressful. Also working in shifts is found to affect job performance, sleep patterns, and social as well as family life adversely. ${ }^{12}$

Because the persistence of post-traumatic symptoms may lead to chronic fatigue, decreased job satisfaction, work absenteeism, or early retirement, ${ }^{13}$ it is important to pay attention to the consequences of acute stressors experienced on a regular basis. In order to get a better understanding of the influence of work related stressors, researchers should include acute as well as chronic stressors in their study design. However, as Day and Livingstone stated,$^{14}$ research concerning both types of stressors is sparse. They examined the impact of acute and chronic stressors on the health of military personnel. Psychological, behavioural, and physical symptoms were associated with acute work related events, lack of job stimulation, ambiguity, and overload. Alexander and Klein found in a sample of ambulance personnel that emotional exhaustion was associated with less job satisfaction, longer time in service, less recovery time between incidents, and more frequent exposure to incidents. ${ }^{15} \mathrm{~A}$ third of the ambulance workers suffered from post-traumatic stress reactions. It can be concluded from these studies that focussing on acute as well as chronic stressors is relevant in research.

In this article we examine the role of acute and chronic stressors in the development of health symptoms in a sample of ambulance workers. These workers are often involved in critical incidents and the direct aftermath. They have to deal with people in panic and distress, and are thereby often confronted with a rather unflattering side of humanity. ${ }^{16}$ Research has indicated that ambulance workers suffer from symptoms related to traumatic events. ${ }^{11}{ }^{15} 17$ Moreover, they experience more chronic stressors in their work than workers in other health service settings. ${ }^{17}$ The purpose of this study is to investigate the predictive effect of both acute and chronic stressors on health symptoms, such as post-traumatic reactions, burnout, and fatigue. The central research question is: Do acute and chronic work related stressors predict poor mental health, in particular post-traumatic stress reactions, burnout, and fatigue?

\section{METHOD \\ Subjects}

Participants were paramedics and drivers from 10 regional ambulance services in the Netherlands. In order to get a representative sample these ambulance services were randomly selected from the total group of 80 services in the Netherlands. Rural as well as urban services were included in the study. At the first measurement, called time 1, 393 questionnaires were distributed by the supervisor of each ambulance service to all personnel of that service. A letter ensuring confidentiality accompanied questionnaires. To encourage an honest response individual survey forms would not be made available to the employers, or to the ambulance service companies. The completed questionnaires were sent to the authors using the enclosed return envelope. For anonymity reasons the addresses were not in the possession of the researchers, therefore reminder letters were sent to all respondents two and four weeks after the initial mailing.

The return rate at time 1 was $56 \%$, with 221 ambulance workers participating. In the questionnaire the respondents were asked to fill in their name and address if they were willing to participate in follow up (time 2). Of the ambulance workers $71 \%$ agreed to participate in future research. One year later 156 questionnaires were sent to these respondents. After three reminders (two, four, and six weeks after the initial mailing) 123 questionnaires were returned (final response rate $31 \%)$.

\section{Measures}

The questionnaire at time 1 included questions concerning demographic items, such as sex, age, and marital status. Specific questions about the acute stressors in the work setting of ambulance workers were formulated. Standardised measures were used to get insight into chronic stressors and health symptoms (post-traumatic stress reactions, burnout, and fatigue).

\section{Acute stressors}

The exposure to acute stressors was examined with questions formulated by the researchers. The respondents were asked how many incidents that were personally disturbing to them they experienced in the last five years. They were asked to indicate the time passed since their last experienced incident. In order to evaluate this last experienced event they had to describe this event. Furthermore, they were asked to rate how stressful a list of specified acute stressors ( 13 items) was to them on a scale from 1 (not stressful at all) to 4 (extremely stressful). Examples of stressors in this list were: dealing with psychiatric patients, involved with dying people, confrontation with young victims, etc. These questions about acute stressors were also asked at time 2. Finally, a subscale of the Questionnaire on the Experience and Assessment of Work (QEAW) ${ }^{18}$ was used to get insight in the presence of emotionally demanding situations compared to employees also working in a health service. This subscale labelled high emotional demands, consisted of seven items. An example of an item is: "Is your job emotionally demanding?". Cronbach's alpha $(\alpha)$ at time 1 was 0.60 .

\section{Chronic stressors}

The QEAW was used to get insight in the presence of common work related stressors at time 1 and time $2 .{ }^{18}$ This questionnaire was validated in a sample of more than 80000 people in various working settings in the Netherlands-for example, industrial, education, and transport sectors. The scores of the ambulance workers were compared with those of employees working in various kinds of health services. Depending on the subscale the size of the reference group ranged from 3409 to 4355. In line with the purpose of this study, the following subscales of this comprehensive instrument were selected: lack of job autonomy (Cronbach's alpha at time $1 \alpha=0.88,11$ items, for example, "Do you have influence on the planning of your work?"); lack of support from colleagues ( $\alpha=0.81$, 9 items, for example, "Are your colleagues friendly to you?"); lack of support from the supervisor $(\alpha=0.89,9$ items, for example, "May you count on your supervisor when you have difficulties in your work?"); poor communication $(\alpha=0.88$, 4 items, for example, "Are you informed about important issues in your organisation?"); lack of information $(\alpha=0.83,7$ items, for example, "Do you receive enough information about the results of your job?"); insufficient financial reward ( $\alpha=0.77,5$ items, for example, "Do you think your company gives good rewards?"); and physical strains $(\alpha=0.81,7$ items, for example, "Is your job physically demanding?"). The items were scored on a four point scale ( $1=$ always, $4=$ never $)$. To interpret the subscales the sum scores were recoded and 
standardised ranging from 0 to 100 . The higher a score, the more the situation was perceived as a stressor.

\section{Health symptoms}

At time 1 and time 2 the questionnaire consisted of standardised scales to assess and predict the following mental health symptoms: post-traumatic stress symptoms, burnout, and fatigue.

The Dutch version of the Impact of Event Scale (IES) was used to determine and predict self reported symptoms of post-traumatic symptoms of intrusion and avoidance in relation with the last experienced critical incident. ${ }^{19} 20$ The IES has seven items designed to assess intrusion, for example, "I had waves of strong feelings about it", and eight items to assess avoidance, for example, "I stayed away from reminders of it". The items are scored on a four point scale $(0=$ never, $1=$ sometimes, $3=$ often, $5=$ always). This questionnaire has been used in numerous studies concerning post-traumatic stress reactions, ${ }^{71521}$ and is widely recommended as a screening instrument for victims after disasters and other extreme situations. ${ }^{22}$ The Dutch version was found to have reliable subscales and the structure was similar to the original version. At time 1 the internal consistency was 0.87 for intrusion, 0.88 for avoidance, and 0.92 for the total score. A score of 26 or higher is an indication of a clinical level of post-traumatic symptoms (indicative for PTSD). ${ }^{21}$ This cut off score is used in the present study to assess the intensity of post-traumatic stress symptoms.

Fatigue was measured at time 1 and time 2 with the Checklist Individual Strength (CIS), ${ }^{23}$ a 20 -item self report instrument. The CIS covers several aspects of fatigue, such as subjective fatigue (eight items, for example, "I get tired very quickly"); concentration (five items, for example, "Thinking requires effort"); motivation (four items, for example, "I feel no desire to do anything"); physical activity (three items, for example, "I don't do much during the day"), and a total score. Items are scored on a seven point Likert scale ( $\mathrm{l}=$ Yes, that is true to $7=$ No, that is not true). Higher scores indicate a higher degree of fatigue. Reliability of the subscales (subjective fatigue, reduced motivation, impaired concentration, and lack of physical activity) were 0.91, 0.82, 0.83, and 0.75 respectively. Cronbach's alpha for the total score of the CIS was 0.94. The mean scores on the subscales and the total score of the ambulance workers were compared with those of a representative group of healthy subjects. This comparison group consisted of 53 adults (73\% female; mean age was 37.1 years; range 19-63). ${ }^{24}$ A cut off point (a CIS total score higher than 76) indicating that an individual is at risk for sick leave or disability was used. ${ }^{25}$

The Dutch version of the Maslach Burnout Inventory (MBI) was used to predict the burnout symptoms at time $2 .^{26}{ }^{27}$ This widely used instrument consists of 15 items assessing the three central dimensions of burnout: emotional exhaustion (five items, "I feel burned out from my job"); cynicism (four items "I am less enthusiastic about my job"); and personal accomplishment ( six items "I deal very effectively with problems my job"). The items were scored on a seven point scale ( 0 $=$ never, $6=$ always $)$. Cronbach's alpha was $0.86,0.76$, and 0.70 at time 1 for the three subscales respectively. Cut off scores were used to assess risk for burnout in ambulance workers. The reference group was a random sample of the Dutch working population $(\mathrm{N}=1111) .^{27}$

\section{Statistical analysis}

Several statistical analyses have been performed in order to answer the research questions. To test whether there is a difference in the presence of chronic stressors as well as a difference in fatigue symptoms between the ambulance workers and the reference group one sample $t$ test have been conducted. Multivariate analyses of variance with repeated measures design have been conducted to investigate whether there is a difference in reported psychological health symptoms in time. To determine the predictive factors of ambulance workers' development of health symptoms, hierarchical multiple regression analyses have been conducted. In two blocks the predictors were stepwise entered into the equation. To control for symptoms at time 1 the following variables were entered in the first block: post-traumatic stress symptoms (IES total), emotional exhaustion (MBI EE), and fatigue (CIS total). Emotional exhaustion was the only subscale of the MBI entered in the equation, because this is considered the most important dimension of burnout. In the second block the acute (number of critical incidents and the subscale high emotional demands of the QEAW) and chronic stressors (subscales of the QEAW) were entered. Separate analyses were conducted for the IES subscales and the total score, the MBI subscales and the CIS total score.

\section{RESULTS}

\section{Demographic characteristics of the ambulance workers}

Most of the ambulance workers were men $(n=189,86 \%)$. Mean age was 39.8 years ((SD) 7.1). Most of them were married $74.4 \%, 12.8 \%$ cohabited, $8.2 \%$ was single, and $4.6 \%$ were divorced. The majority had one or more children living with their parents $(\mathrm{n}=145,65.9 \%)$. Mean working experience at the public health service at time 1 was 9.3 (7.0) years. Most of the respondents (90.9\%) worked full time. Although the questionnaire was sent to an equal number of paramedics and drivers, the majority of the participants were paramedics $(57.5 \%)$.

\section{Acute stressors at time 1}

At time 1,85\% of all ambulance workers experienced one or more critical incidents in the last five years. The descriptions of the experiences could be divided in six categories: examples of those experiences were events involving dead children (25\%), followed by medical emergencies $(23 \%)$, severe accidents or injuries $(21 \%)$, acts of violence or threats $(13 \%)$, suicide (attempts) (10\%), and organisational problems (8\%)-for example, lack of acknowledgement by a superior after a critical incident, or false or insufficient information about the site of the accident or the condition of the victims. The majority (66\%) experienced the last disturbing incident less than one year ago. The mean time past since the last experienced incident was 14.3 (16.8) months. The mean number of reported events was 3.7 (1.5). Almost half of the respondents (45\%) experienced four or more critical incidents in the previous five years. Furthermore, the ambulance workers rated how stressful a list of specified acute stressors was to them. The three most stressful events the ambulance workers were exposed to were: confrontation with deceased children $(M=2.7(0.90))$, confrontation with people in despair $(M=2.4(0.54))$, and confrontation with children of sexual abuse (for example, assault or rape) $(\mathrm{M}=2.3(0.96))$.

Compared to the reference group the ambulance workers scored significantly higher on the subscale high emotional demands of the QEAW at time 1. This indicates that the ambulance workers perceived their job as more emotional demanding than employees of various health services. (For statistical details see Table 1.)

\section{Chronic stressors at time 1}

With regard to chronic work related stressors the ambulance workers differed from the reference group at time 1 on all included subscales with exception of the subscale lack of information of the QEAW. The ambulance workers scored higher than the reference group, which means that they reported more chronic work related stressors (table 1). 
Table 1 Means and standard deviations of ambulance personnel and a reference group on the Questionnaire on the Experience and Assessment of Work

\begin{tabular}{|c|c|c|c|c|c|c|c|c|}
\hline \multirow[b]{2}{*}{ Subscales of QEAW } & \multicolumn{2}{|c|}{$\begin{array}{l}\text { Ambulance } \\
\text { workers }(n=221)\end{array}$} & \multicolumn{3}{|c|}{ Reference groups } & \multirow[b]{2}{*}{$t$} & \multirow[b]{2}{*}{ df } & \multirow[b]{2}{*}{$\mathrm{p}$ Value } \\
\hline & M & SD & M & SD & $\mathrm{n}$ & & & \\
\hline Poor communication & 52.2 & 21.2 & 47.7 & 20.7 & 3656 & 3.3 & 220 & $<0.01$ \\
\hline Insufficient financial reward & 54.3 & 21.6 & 50.2 & 23.1 & 3409 & 2.8 & 218 & $<0.01$ \\
\hline High emotional demands & 39.5 & 9.7 & 34.4 & 14.9 & 4171 & 7.7 & 220 & $<0.001$ \\
\hline Lack of information & 48.6 & 16.6 & 49.3 & 18.6 & 3850 & -0.61 & 220 & NS \\
\hline Lack of support from colleagues & 25.6 & 11.4 & 22.0 & 13.9 & 3953 & 4.7 & 220 & $<0.001$ \\
\hline Lack of support from supervisor & 32.6 & 17.2 & 23.1 & 17.6 & 4316 & 7.4 & 220 & $<0.001$ \\
\hline Physical strains & 40.0 & 15.4 & 26.4 & 21.1 & 4172 & 13.2 & 220 & $<0.001$ \\
\hline Lack of job autonomy & 57.1 & 17.7 & 42.8 & 17.9 & 4355 & 11.9 & 219 & $<0.001$ \\
\hline
\end{tabular}

\section{Health symptoms}

\section{Post-traumatic responses}

The ambulance workers who indicated that they experienced at least one critical incident filled in the IES (at time $1 \mathrm{n}=187$ and at time $2 \mathrm{n}=112$ ). Means and standard deviations of the IES of those who participated at both time points are presented in table 2. MANOVA repeated measures showed no significant differences between the scores at time 1 and at time 2 .

According to Chemtob et al, ${ }^{21}$ a score of 26 or higher is an indication of a clinical level of post-traumatic distress (indicative for PTSD). From those who indicated at time 1 that they were exposed to at least one critical incident in the last five years $12 \%(n=22)$ suffered from a clinical level of distress. At time 2, 13\% $(n=15)$ suffered from this level of post-traumatic distress.

\section{Fatigue}

Means and standard deviations on the CIS at both measurements are presented in table 2. MANOVA repeated measures showed no differences in time on the CIS. The ambulance workers differed from the reference group at time 1 on the following subscales: motivation $(t(211)=3.5 ; \mathrm{p}<0.01)$, physical activity $(t(213)=4.2 ; \mathrm{p}<0.001)$, concentration $(t(211)=4.8$; $\mathrm{p}<0.001)$, and the total score $(t(210)=3.2 ; \mathrm{p}<0.01)$. The ambulance workers significantly scored higher, indicating that they reported more symptoms. According to Bültmann et al, ${ }^{25}$ a score $>76$ on the total score of the CIS is an indication of a fatigue level that puts the individual at high risk for subsequent sick leave or work disability. In this sample $10 \%(n=21)$ scored above the cut off point of the CIS at the time 1.

\section{Burnout}

Means and standard deviations at both measurements are presented in table 2. MANOVA repeated measures indicated a significant difference on the subscale cynicism in time. At time 2 the ambulance personnel reported more cynicism than at time 1. According to the criterion of Schaufeli and van Dierendonck, ${ }^{27}$ almost $12 \%$ scored $(n=26)$ high on exhaustion, almost $18 \%(n=39)$ scored high on cynicism, and $16 \%$ $(n=36)$ scored low on competence at time l. Of the ambulance workers $8.6 \%(n=19)$ met the criteria of risk for burnout. In table 2 the interrelations between the subscales of the IES, CIS, and MBI are presented. In the upper half of the matrix the interrelations between time 1 and time 2 are presented and in the lower half of the matrix the interrelations between the subscales at time 1 are given.

\section{Relation between acute and chronic stressors and mental health}

In order to get insight in the association between both kinds of stressors at time 1 and health symptoms at time 2, Pearson correlations are presented in table 3. Lack of social support from colleagues as well as lack of social support from the supervisor were found to be associated with almost all health symptoms. Insufficient financial reward was not associated with any of the health symptoms. The frequency of acute stressors was related to fatigue, burnout symptoms, and posttraumatic stress reactions.

\section{Prediction of symptomatology}

Post-traumatic responses

Table 4 presents the results of the multiple regression analyses of the IES subscales. After controlling for symptoms at time 1 no variables entered in the second block were found to be significant predictors of intrusion. IES total score at time 1 explained $30.7 \%$ of the variance of intrusion at time 2 . After controlling for symptoms at time 1 (IES total explained $21 \%$ of the variance), IES avoidance at time 2 could be predicted by poor communication that accounted for $9 \%$ of the variance. A further $3 \%$ of the variance was explained by high emotional demands. In total $33 \%$ of the variance of IES avoidance was explained. Poor communication at time $\mathrm{l}$ showed to be a significant predictor of IES total after controlling for symptoms at time 1 (IES total accounted for 30\% of the variance). Poor communication accounted for an additional $5 \%$ of the variance.

\section{Burnout symptoms}

The results of the multiple hierarchical regression analyses of the MBI subscales are presented in table 4. MBI emotional exhaustion could be significantly predicted by poor communication and physical strains after controlling for symptoms at time 1 (MBI emotional exhaustion (44\% of the variance) and IES total score (additional 2\%) were significant). These two chronic stressors accounted both for 3\% of the variance of emotional exhaustion. After controlling for symptoms at time 1 lack of social support from the supervisor was found to be a significant predictor of MBI cynicism at time 2. Emotional exhaustion at time $\mathrm{l}$ and lack social support from the supervisor accounted both for $8 \%$ of the variance. Lack of social support from colleagues and lack of social support from the supervisor showed to be significant predictors of MBI personal accomplishment after controlling for symptoms at time 1 (CIS total score and IES total score). Lack of social support from colleagues accounted for an additional $7 \%$ of the variance and lack of social support from the supervisor for $2 \%$ after CIS total score (19\% of the variance) and IES total (an additional $4 \%$ of the variance).

\section{Fatigue}

Table 4 presents the results of the multiple regression analysis of the CIS total scores. Lack of social support from the supervisor was found to be a significant predictor of CIS total score at time 2 after controlling for symptoms at time 1 (CIS total (24\% of the variance) and IES total score (an additional $6 \%$ of the variance). Lack of social support from the supervisor accounted for an additional 3\% of the variance. 


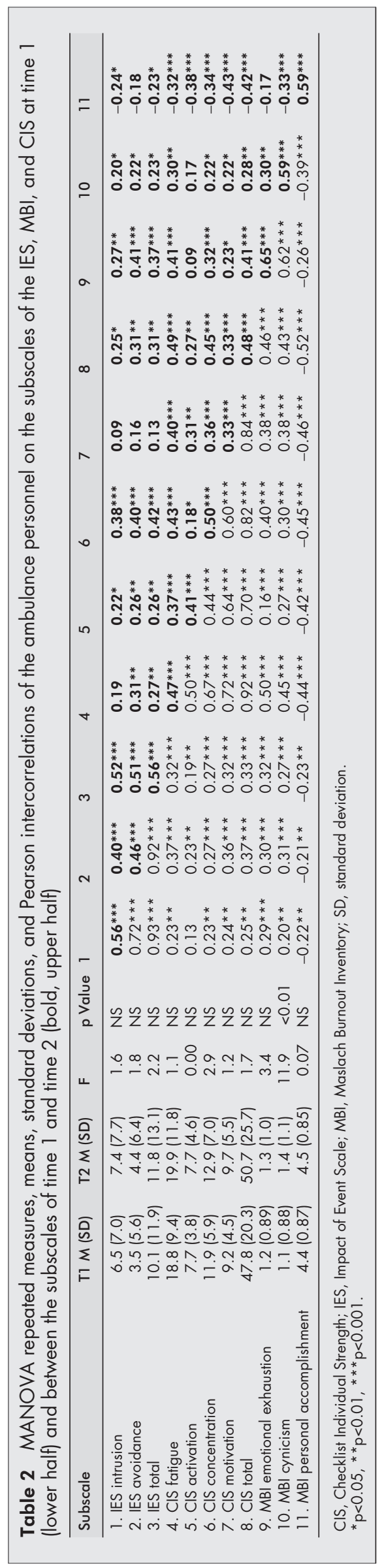

\section{DISCUSSION}

This study focused on acute and chronic job stressors in relation to various mental health problems in a representative sample of ambulance service personnel. A substantial proportion of the ambulance workers (85\%) were confronted with at least one critical incident in the last five years. Incidents involving children and dealing with sad and hopeless patients were rated as most stressful. A substantial minority of the emergency workers (12\%) suffered from severe post-traumatic symptoms after experiencing one or more critical incidents, in particular severe intrusions and avoidances. In line with earlier studies, ${ }^{911}$ the findings indicate that emergency workers may be at risk of developing PTSD, even if they are not exposed to major disasters.

Although the number of acute stressors was significantly associated with post-traumatic symptoms, this variable appeared to not be a significant predictor of health symptoms one year after the first assessment. High emotional demands, for instance, experienced at time 1 significantly predicted avoidances at time 2 . Other significant predictors of posttraumatic responses at time 2 were poor communication at time 1 and earlier reported symptoms of avoidances and intrusions. Various other studies have concluded that traumatic events may have long term and serious consequences for mental health. ${ }^{28}$ Based on the correlations between health symptoms of time 1 and time 2, MANOVA (repeated measures) as well as the results of the multiple regression analyses, it may be concluded that reported health symptoms appear to be stable in time. This may confirm the conclusion that traumatic events, but also chronic stressors have enduring consequences for psychological health.

A remarkable proportion of ambulance workers also reported fatigue. They were significantly more tired than a reference group. A tenth of our sample showed a fatigue level that puts an individual "at risk" for subsequent sick leave or work disability. The percentage of risk for burnout (8.6\%) was reasonably high as well, especially in comparison with the percentage of burnout cases in the general working population of the Netherlands $(5.25 \%)$. $^{30}$

The results of the MANOVA repeated measures showed that the various health symptoms were stable in time. Only on the subscale cynicism of the MBI a significant increase of symptoms in time was found. The best predictors of symptoms at time 2 were symptoms at time 1 . This stability could be explained by the fact that the sample is a rather homogeneous group and their job conditions stay rather equal.

Although they have to deal with a diversity of incidents, most ambulance workers are able to cope with these events reasonably well. They appreciate their profession, in particular, taking care for patients may be rewarding and satisfying which makes it possible to cope with the negative aspects of the job. Earlier research on ambulance personnel has indicated that providing care for others is personally gratifying and rewarding. ${ }^{31}$ Alexander and Klein reported indeed high levels of job satisfaction among ambulance workers. ${ }^{15}$ However, a distinction between satisfaction with regard to the job and satisfaction with regard to the organisation can be made. Expressed job satisfaction does not mean that the organisation does not have to concerned about the well being of its employees. Dissatisfaction with organisational aspects has a price: a price to be measured in terms of the levels of general psychopathology, burnout, and post-traumatic symptoms.

In this study high levels of chronic stressors were quite common in ambulance workers. These stressors showed to be significant predictors of health symptoms. Especially social aspects of the work environment were important predictors, in particular lack of social support from colleagues, lack of social support from the supervisor, and finally poor communication. These factors were found to be significant predictors of post-traumatic response, burnout symptoms, and fatigue. 
Table 3 Pearson correlations between acute and chronic stressors at time 1 and psychological distress at time 2

\begin{tabular}{|c|c|c|c|c|c|c|c|c|c|c|c|}
\hline & CIS-fat & CIS-con & CIS-mot & CIS-act & CIS-tot & MBI-EE & MBI-DEP & MBI-PA & IES-in & IES-av & IES-tot \\
\hline Number of events & 0.18 & 0.15 & 0.16 & 0.15 & $0.19 *$ & $0.30 * *$ & $0.20 *$ & -0.18 & $0.33 * * *$ & 0.26 ** & 0.32 ** \\
\hline $\begin{array}{l}\text { Lack of social support from } \\
\text { colleagues }\end{array}$ & 0.28 ** & $0.39 * * *$ & $0.34^{* * *}$ & $0.35^{* * *}$ & $0.38 * * *$ & 0.29 ** & $0.27^{* *}$ & $-0.42^{* * *}$ & $0.19 *$ & 0.15 & 0.19 \\
\hline $\begin{array}{l}\text { Lack of social support from } \\
\text { supervisor }\end{array}$ & $0.39 * * *$ & $0.40 * * *$ & $0.40 * * *$ & $0.32 * * *$ & $0.43^{* * *}$ & $0.41 * * *$ & $0.40 * * *$ & $-0.34 * * *$ & 0.32 ** & 0.24 * & 0.31 * * \\
\hline Poor communication & $0.18^{*}$ & 0.09 & $0.19^{*}$ & 0.05 & 0.15 & 0.26 ** & 0.12 & -0.09 & 0.15 & 0.31 ** & $0.23^{*}$ \\
\hline Insufficient financial reward & 0.03 & 0.12 & -0.02 & 0.04 & 0.05 & 0.09 & -0.05 & 0.11 & 0.15 & 0.09 & 0.13 \\
\hline Lack of job autonomy & 0.18 & $0.25^{* *}$ & $0.23^{*}$ & 0.17 & $0.22^{*}$ & 0.25 ** & 0.18 & $-0.28^{* *}$ & $0.22 *$ & 0.11 & 0.18 \\
\hline High emotional demands & 0.16 & 0.17 & 0.11 & 0.12 & 0.17 & 0.27 * * & 0.26 ** & -0.14 & $0.23^{*}$ & 0.32 ** & 0.29 * * \\
\hline Physical strains & 0.24 ** & $0.27 * *$ & 0.15 & 0.09 & $0.23^{*}$ & $0.35^{* * *}$ & 0.16 & -0.10 & $0.33^{* * *}$ & $0.23^{*}$ & 0.31 ** \\
\hline
\end{tabular}

IES-in = Impact of Event Scale-intrusion; IES-av = Impact of Event Scale-avoidance; IES-tot = Impact of Event Scale-total; MBI-EE = Maslach Burnout Inventory-Emotional Exhaustion; MBI-CY = Maslach Burnout Inventory-Cynicism; MBI-PA = Maslach Burnout Inventory-Personal Accomplishment; CIS-tot = Checklist Individual Strength-total. CIS-fat = Checklist Individual Strength-fatigue; CIS-act = Checklist Individual Strength-activation; CIS-con = Checklist Individual Strength-concentration; CIS-mot = Checklist Individual Strength-motivation .

${ }^{*} p<0.05,{ }^{* *} p<0.01,{ }^{* *} p<0.001$.

Therefore, improving job circumstances is more a matter of improving the social climate, and enhancing acknowledgement as well as attention-in short management of people instead of management of organisational procedures and technical elements. Taking part in decision making, and being informed about important issues within the organisation should be adequately arranged in order to prevent health symptoms.

This study has some limitations. In research on the consequences of traumatic or critical incidences the response rate is often low. ${ }^{32}$ This is an important issue, because people who refused to participate in traumatic stress research have been found to have more health problems. ${ }^{32}$ The response rate at time 1 in this study is $56 \%$. Since it is suggested that psychological impact of their work on emergency workers is underreported, ${ }^{33}$ such a selection bias would mean that the percentages of health symptoms are underestimated. Additionally, it was not possible to send a follow up questionnaire to all ambulance workers. Consequently, there may be some selection bias, because only those who indicated at time 1 that they were willing to participate were included in the second measurement. Another limitation of this study is that it is retrospective. However, a prospective study is hard to realise in the field of trauma research. A time consuming solution would be to examine ambulance workers who have just started with their job and follow them during a period of some years to investigate which factors are predictive for health symptoms.

Several questionnaires measuring health symptoms were used in the present study. From the Pearson intercorrelations between the subscales of the IES, MBI, and CIS it may be concluded that these instruments have good psychometric properties in terms of convergent and discriminative validity. They also appeared quite stable in time (test-retest reliability). Since in various European countries the employer is obliged by law to take care of employees who have been affected by critical incidents, it is important to have insight in the association between acute and chronic stressors in relation to the well being of the employee. This insight is necessary for developing appropriate interventions to prevent work related stress symptoms. Until now, these interventions have focused either on stress

Table 4 Results of stepwise multiple regression analyses of health symptoms (IES, $\mathrm{MBI}$, and $\mathrm{CIS}$ total) at time 2

\begin{tabular}{|c|c|c|c|c|c|c|}
\hline Outcome & Step & Predictor & Total $\mathrm{R}^{2}$ & Beta & SE & $\mathrm{p}$ Value \\
\hline IES-in & 1 & IES-tot & 0.31 & 0.56 & 0.06 & $<0.001$ \\
\hline \multirow[t]{3}{*}{ IES-av } & 1 & IES-tot & 0.21 & 0.41 & 0.05 & $<0.001$ \\
\hline & 2 & Poor communication & 0.30 & 0.27 & 0.03 & $<0.01$ \\
\hline & 3 & High emotional demands & 0.33 & 0.20 & 0.07 & $<0.05$ \\
\hline \multirow[t]{2}{*}{ IES-tot } & 1 & IES-tot & 0.30 & 0.55 & 0.10 & $<0.001$ \\
\hline & 2 & Poor communication & 0.35 & 0.22 & 0.05 & $<0.05$ \\
\hline \multirow[t]{4}{*}{ MBI-EE } & 1 & MBI-EE & 0.44 & 0.53 & 0.09 & $<0.001$ \\
\hline & 2 & IES-tot & 0.46 & 0.14 & 0.008 & 0.075 \\
\hline & 3 & Poor communication & 0.49 & 0.16 & 0.003 & $<0.05$ \\
\hline & 4 & Physical strains & 0.52 & 0.17 & 0.005 & $<0.05$ \\
\hline \multirow[t]{2}{*}{ MBI-DEP } & 1 & MBI-EE & 0.08 & 0.16 & 0.12 & 0.13 \\
\hline & 2 & Lack of support from supervisor & 0.16 & 0.31 & 0.01 & $<0.001$ \\
\hline \multirow[t]{4}{*}{ MBI-PA } & 1 & CIS-tot & 0.19 & -0.19 & 0.004 & 0.060 \\
\hline & 2 & IES-tot & 0.23 & -0.17 & 0.007 & $<0.05$ \\
\hline & 3 & Lack of support from colleagues & 0.30 & -0.23 & 0.008 & $<0.05$ \\
\hline & 4 & Lack of support from supervisor & 0.32 & -0.20 & 0.005 & $<0.05$ \\
\hline \multirow[t]{3}{*}{ CIS-tot } & 1 & CIS-tot & 0.24 & 0.30 & 0.12 & $<0.01$ \\
\hline & 2 & MBI-EE & 0.30 & 0.22 & 2.81 & $<0.05$ \\
\hline & 3 & Lack of support from supervisor & 0.33 & 0.22 & 0.16 & $<0.05$ \\
\hline \multicolumn{7}{|c|}{$\begin{array}{l}\text { IES-in = Impact of Event Scale-intrusion; IES-av = Impact of Event Scale-avoidance; IES-tot = Impact of Event } \\
\text { Scale-total; MBI-EE = Maslach Burnout Inventory-Emotional Exhaustion; MBI-CY = Maslach Burnout } \\
\text { Inventory-Cynicism; MBI-PA = Maslach Burnout Inventory-Personal Accomplishment; CIS-tot = Checklist } \\
\text { Individual Strength-total. }\end{array}$} \\
\hline
\end{tabular}


management or on trauma counselling. ${ }^{34}$ From our research is known that both acute as well as chronic stressors have their impact on the well being of the worker. Therefore, occupational interventions and care after trauma should be integrated.

It has been shown that preparing the helpers in what they are going to face is useful in preventing health symptoms. ${ }^{35}$ During training attention should be paid to the different kinds of stressful aspects of the work and during structured meetings in the work setting it is of importance to pay attention to critical incidents and their aftermath. ${ }^{34}{ }^{36}$ Talking with colleagues after a critical incident appears to be helpful in preventing harmful outcomes. ${ }^{157}$ Alexander and Wells emphasised the psychoprophylactic role of a good organisation and sensitive staff management practices. ${ }^{35}$ Jones et al demonstrated that the perception of a supportive organisation correlates strongly and negatively with the amount of work stress. ${ }^{38}$ When implementing a workplace intervention following traumatic events support and acknowledgement from management are of vital importance. ${ }^{39}$ This study demonstrated that organisational aspects, in particular lack of social support at work and poor communication, are of vital importance in the development of work related health symptoms.

\section{ACKNOWLEDGEMENTS}

The present study is supported by a grant from the Netherlands Organisation for Scientific Research (NWO grant No. 580-02.205).

\section{Authors' affiliations}

E van der Ploeg, Department of Clinical Psychology, Utrecht University, The Netherlands

R J Kleber*, Department of Clinical Psychology, Utrecht University, The Netherlands

*R J Kleber is also affiliated at Department of Clinical Health Psychology, Tilburg University, The Netherlands and Institute for Psychotrauma, Zaltbommel, The Netherlands.

\section{REFERENCES}

1 Tennant C. Work-related stress and depressive disorders. J Psychosom Res 2001;51:697-704

2 Paton D, Smith LM. Psychological trauma in critical occupations: methodological and assessment strategies. In Paton D, Violanti JM (eds) Traumatic stress in critical occupations: recognition, consequences and treatment. Springfield, IL: Charles C Thomas Publishers, 1996.

3 Beaton R, Murphy S, Johnson C, et al. Exposure to duty-related incident stressors in urban firefighters and paramedics. J Trauma Stress $1998 ; 11: 821-8$

4 Mitchell JT, Dyregrov A. Traumatic stress in disaster workers and emergency personnel: prevention and intervention. In Wilson JP, Raphael B (eds). International handbook of traumatic stress syndromes. New York: Plenum Press, 1993: 905-14

5 American Psychiatric Association. Diagnostic and statistical manual of mental disorders (4th ed) (DSM-IV). Washington, DC: American Pyschiatric Association, 1994

6 McFarlane AC, Papay P. Multiple diagnoses in post-traumatic stress disorder in the victims of a natural disaster. J Nerv Ment Dis 1992; 180:498-504

7 Ursano RJ, Fullerton CS, Kao T, et al. Longitudinal assessment of post-traumatic stress disorder and depression after exposure to traumatic death. J Nerv Ment Dis 1995;183:36-42.

8 Beaton RD, Murphy SA. Working with people in crisis. In Figley CR (ed). Compassion fatigue: coping with secondary traumatic stress disorder in those who threat the traumatized. New York: Brunnel/Mazel Publishers, 1995:51-81.

9 Marmar CR, Weiss DS, Metzler TJ, et al. Stress responses of emergency services personnel to the Loma Prieta earthquake interstate 880 freeway collapse and control traumatic events. J Trauma Stress 1996;9:63-85.

10 Genest $M$, Levine J, Ramsden V, et al. The impact of providing help: emergency workers and cardiopulmonary resuscitation attempts. J Trauma Stress 1990;3:305-13.

11 Clohessy S, Ehlers A. PTSD symptoms, response to intrusive memories and coping in ambulance service workers. Br J Clin Psychol 1999;38:251-64.

12 Monk TH. Shiftworker performance. In Scott AJ (ed). Occupational medicine state of the art reviews 5:2-shiftwork. Hanley and Belfus: Philadelphia, 1990: 183-98.
13 Hall RC, Gardner ER, Perl M, et al. The professional burnout syndrome. Psychiatr Opin 1979;16:12-17.

14 Day AL, Livingstone HA. Chronic and acute stressors among military personnel: do coping styles buffer their negative impact on health? J Occup Health Psychol 2001;6:348-60.

15 Alexander DA, Klein S. Ambulance personnel and critical incidents: impact of accident and emergency work on mental health and emotional well-being. Br J Psychiatry 2001;178:76-81.

16 James A. Perceptions of stress in British ambulance personnel. Work Stress 1988;2:319-26.

17 van der Ploeg E, Kleber RJ. Ingriipende gebeurtenissen op het werk and en chronische: Een studie bii ambulancepersoneel [Impact of critical events and chronic stress at work: a study among ambulance personnel]. Gedrag \& Organisatie 2001;14:142-51.

18 van Veldhoven M, Meijman TF, Broersen JPJ, et al. Handleiding VBBA: onderzoek naar de beleving van psychosociale arbeidsbelasting en werkstress met behulp van de vragenlijst beleving en beoordeling van de arbeid [Manual of the QEAW: research on the evaluation of psychosocial work strain and job stress using the Questionnaire on the Experience and Assessment of Work]. Amsterdam: SKB, 1997.

19 Brom D, Kleber RJ. De Schok Verwerkings Lijst [The Dutch Impact of Event Scale]. Ned Tiidschr Psychol 1985;40:164-8.

20 Horowitz MJ, Wilner N, Alvarez W. The impact of event scale: a measure of subjective stress. Psychosom Med 1979;41:209-18.

21 Chemtob CM, Tomas S, Law W, et al. Postdisaster psychosocial intervention: a field study of the impact of debriefing on psychological distress. Am J Psychiatry 1997;154:415-17

22 Raphael B, Lundin T, Weisaeth L. A research method for the study of psychological and psychiatric aspects of a disaster. Acta Psychiatr Scand 1989:80(suppl 353):1-75

22 a van der Ploeg E, Mooren TTM, Kleber RJ, et al. Construct validation of the Dutch version of the Impact of Event Scale. Psychological Assessment 2003; (in press).

23 Vercoulen JHMM, Swannink CMA, Fennis JFM, et al. Dimensional assessment of chronic fatigue syndrome. J Psychosom Res 1994;5:383-92

24 Vercoulen JHMM, Hommes OR, Swannink CMA, et al. The measurement of fatigue in patients with multiple sclerosis: a multidimensional comparison with patients with chronic fatigue syndrome and healthy subjects. Arch Neurol 1996;53:642-9.

25 Bültmann U, de Vries M, Beurskens AJHM, et al. Measurement of prolonged fatigue in the working population: determination of a cutoff point for the checklist individual strength. J Occup Health Psychol 2000;5:411-16.

26 Maslach C, Jackson SE. Maslach Burnout Inventory: manual research edition. Paolo Alto, CA: University of California, Consulting Psychologist Press, 1986.

27 Schaufeli WB, van Dierendonck D. UBOS: Utrechtse Burnout Schaal-handleiding [UBOS: Utrecht Burnout Scale-manual]. Lisse, The Netherlands: Swets \& Zeitlinger BV, 2000.

28 van der Kolk BA, McFarlance AC, Weisaeth L. Traumatic stress: the effects of overwhelming experience on mind, body, and society. New York: The Guilford Press, 1996.

29 Kleber RJ, Brom D, Defares PB. Coping with trauma: theory, prevention and treatment. Lisse, The Netherlands: Swets \& Zeitlinger, 1992.

30 Houtman ILD, Schaufeli WB, Taris T. Psychische vermoeidheid en werk [Mental fatigue and work]. Alphen aan den Rijn, The Netherlands: Samsom, 2000

31 James A, Wright I. Occupational stress in the ambulance services. Health Manpow Manage 1991;17:4-11.

32 Weisaeth $\mathbf{L}$. Importance of high response rates in traumatic stress research. Acta Psychiatr Scand 1989;80(suppl 355):131-7.

33 Gibbs MS, Drummond J, Lachenmeyer JR. Effects of disaster on emergency workers: a review with implications for training and post disaster interventions. J Soc Behav Pers 1993;8:189-212.

34 van der Velden PG, Hazen KHM, Kleber RJ. Traumazorg in organisaties [Trauma care in organizations]. Gedrag \& Organisatie 1999;6:397-412.

35 Alexander DA, Wells A. Reactions of police officers to body-handling after a major disaster: a before-and-after comparison. Br J Psychiatry 1991;159:547-55

36 Brom D, Kleber R, Defares PB. Brief psychotherapy for post-traumatic stress disorders. J Consult Clin Psychol 1989;57:607-12.

37 Stephens C, Long N. Communication with police supervisors and peers as a buffer of work-related traumatic stress. Journal of Organizational Behavior 2000;21:407-24.

38 Jones B, Flynn DM, Kelloway K. Perceptions of support from the organization to work stress, satisfaction, and commitment. In SL Sauter, LR Murphy (eds). Organizational risk factors for job stress. Washington, DC: American Psychological Association, 1995:41-53.

39 Stephens C. Debriefing, social support and PTSD in the New Zealand police: testing a multidimensional model of organizational traumatic stress. The Australasian Journal of Disaster and Trauma Studies. 1997-1. http://www.massey.ac.nz/ trauma/issues/1997-1/contents.shtml\#cvs 1 (date last accessed 3 February 2000) 